\title{
Comparison of Iranian Mosques Architecture in Three Dynasties
}

\author{
Mohammad Joos hesh", Negar Kolahi \\ Undergraduate student of Architecture, Department of Architecture, Faculty of Art and Architecture, Mashhad Branch, Islamic Azad \\ university, Mashhad, Iran
}

\begin{abstract}
Present article tries to assess three Iranian mosques architecture during 1000- 1700 A.D. based on architecture styles and different kingdoms. According to this, Khorasani, A zeri and Is fahani styles were compared in Jameh, Goharshad and Sheikh Lotf Allah mosques.
\end{abstract}

Keywords Iranian mosques, Is fahani style, Safavid period, Goharshad mosque, Jameh mosque

\section{Introduction}

Classical architecture, especially temple in general and mosque in particular is the image of the cosmos or man in his cosmic feature. The human body is the temple where spirit has settled in. Monotheistic view of tradition, not only comprises architecture and its entirety, but also includes every architectural element such as space, shape, color, light and matter. Since the unitarianis $m$ view which is stressed in Islam does not deem anything beyond its gamut and does not recognize the sphere of earthly wisdom, the entire Islamic architecture, whatever its employment, is perceived as an utter sacred architecture as mosque in its traditional position[1].

Iran's Islamic architecture is influenced by two major branches: What is outside the indigenous culture of Iran and What belongs to the indigenous culture of Iran before Islam.

Application of arch, vault and dome on square base and veranda are derived from the Parthian (250-226 BC), Sassanid (224-652 BC) and Achaemenid period (559-321 BC.)[2]. With the commencement of Islam, Iranian architecture was influenced by China and the West piecemeal and subsequently new materials were replaced and emerged in the construction of mosques.[3]. Iranian Is lamic architecture principles include:

Human adaptation: It means having human scale, i.e. a room is contemplated in terms of human needs.

Nyaresh: This term refers to things that sustain the structure. Including the static, building technology and materials science.

Self-efficacy means providing the material from the

* Corresponding author:

Javid_11977@yahoo.com (Mohammad Jooshesh)

Published online at http://journal.sapub.org/arch

Copyright (C) 2012 Scientific \& Academic Publishing. All Rights Reserved nearest locations with the lowest price.

Introspection, the existence of the outdoor courtyard in the center of the structure[4]

\section{Aesthetic Elements of Islamic Architecture in Iran}

Light is the main characteristic of Iranian architecture, a symbol of divine wisdom and the manifestation of God that finds expression in his home which is the mosque. It also has an prominent role in reducing the rigidity and frigidity of stone and structure.

As a result, sleek, polished tiles on floors and sometimes mirror work in ceiling are utilized to bring forth a beautiful reflection of light. Color is attained through light amplification and it represents a plurality which has innate connection with unity. White is the symbol of absolute being, sacredness, purity and tranquility which can be observed in the interior design of the mosque. Azure portrays the area within and the immensity of the sky, turquoise is the symbol of sanctity and yellow as the brightest color depicts brightness and light which are a symbol of insight and comprehending. Green with the combination of yellow and blue, is a sign of peace and hope and it is a mixture of science and faith. Black which is fortify ing, covers Caaba and it is the primary symbol of God. Water is the foundation of life that cleanses filth. Water in the mosque is not only used for cleansing of eremites but also it reduces the rigidity of the structure. Water discoloration summons man toward discoloration and unpretentiousness, and its fluidness accentuates the frailty of the edifices that human-beings construct for their eternity. A different application of water in mosque is to reflect the image of the building in itself which creates a mirror for the observer.[5].

The mosque is a place for worship and prayer. Man is striving to migrate to the spiritual city and reach from 
ignorance to lore and through traveling this way his spirit will be discovered and the flesh is the means of this move. Accordingly, he has made places where he can unite the soul and body. Including, Iranian mosques which while creating a visual pleasure, induce a journey in spirituality to man. Mosques predominantly follow a fairly similar pattern and include common elements such as bedchamber, dome, cloister, courtyard, portico and the altar which are constructed in the direction of Qiblah (Caaba) in Mecca. The altar is analogized to rainbow and the arched portico is analogized to mountain which reflect nature. Different parts of mosques are following: Lighthouse or minarets with the meaning of focus of light, is one component of the mosque which were made in the past as a guide for pedestrians lost in the desert and awakening of the sleeping souls. However, the minaret is an expression of divine guidance and direction. Dome With the regular division, the basis of which is a circle and is an image of an infinite whole, to regular polygons, one can discern smaller stars resembling polygons. The concept of dividing the circle into equal arcs is a symbol of unity and plurality to achieve unity. i.e all creations in the world with the plurality at the same time are an indication of the Almighty. Since the do me overlooks the sky, tree of heaven (Tuba), is the best to decorate the interior surface. Using inverted tree indicates the world image in a mirror and is a symbol of heaven. The dome is usually built on a square or polygon and Iranian do mes are conical, joined and discrete. Pool in the mosque, is located in the center of the courtyard which has flowing water. The pool is the mirror of water, image of the sky and seven color tiles. Thus, this is the mirror that makes possible the visit of the sky and the earth. Myansra or apron: which is the central courtyard features Islamic architecture and it is considered to be the resting place for travelers and a cleansing spot that is usually rectangular, square or polygonal. Apron is the access point to the bedchamber. The cloister, which has been popular since the Parthian period, consists of a vault and is opened and closed to apron from three sides. This element has input and output spaces which prevents sunshine and causes the airflow and it is decorated by Muqarnas and brickwork, stucco and tile work. Cloister is referred to the columned indoors existing around the apron. The columned bedchambers have low height and are located around the dome. The altar which is usually located on the south side wall of the mosque with regards to the direction of qiblah is hollow or sunken into a part of the wall. Most mosques were made in the city center, close to markets and the city hall vicinity and provided the city needed more mosques, they were built by the government or philanthropists. The mosque was of major significance that if there were no mosques in a town, that town would be considered trivial. The plan structure of the mosque was mainly single porch, double porch and four porch and a combinations of four arches and porch which was derived from the architecture of Parthian and Sasanid period.

\section{Results}

The study focuses on the comparis on of the architecture of three mosques in three reigns, which are built in three different styles

- Jāmeh Mos que of Isfahān, Khor as ani style, Seljukid period. This dynasty was founded in the eleventh century by the Ghaz Turks who came to Iran and Minor Asia in order to occupy the fertile lands of Transoxania.

Art flourish in this period was owed to the political peace of that period and one of the significant art works of Seljukid period is the Jāmeh Mosque of Is fahān. Jameh mosque of Is fahan or Friday mosque, would be considered as the oldest historic monument. The present façade of the building mostly relates to the Seljukid dynasty, however, the upkeep and expansions refers to later period, especially that of Safavids. Archeological excavations, however, shows signs of the previous kingdoms before Seljukid, such as Al-E-Buyeh and the third A.H. Pre-Islamic signs were spotted in these excavations.

There are a variety of entrances to the building, each of which relates an area to the surrounding environment; the entrances have not been built at the same time though they were designed in difference times in relation to the inside and outside the building. The crossways around the mosque proves the significant relation between the mosque with the ancient part of the city.

Jameh Mosque of Is fahan has been built on a four-cloister basis; based on various references and due to the collection of artistic and architectural innovations of the 13 Islamic centuries, it is proven that the building was damaged and rebuilt due to conflagration and multiple wars, in addition to the unrests in different periods. The mosque has been built in Khorasani style, following pillared bedchamber plan while the plan has changed to the four-cloister in Razi style. The four clo isters around the square clarify the Persian style of mosque construction which has affected other mosques as well. The cloisters which are named Sofeh Saheb in the South, Sofeh Darvish in the North, Sofeh Ostad in the West and Sofeh Shagerd in the East of the building with muqarnas and adornments, elucidate one of the interesting techniques of Persian architecture. None of these four cloisters contain a completely blocked rib while the open rib of the cloisters is toward the apron of the mosque; the walls of the other three ribs lead to the bedchambers and surrounding salons.

The internal surface of the mosque, the minaret and tiles are related to the $15 \mathrm{~A}$.D which are likely related to the same period. The present main building of the mosque includes following parts: The bedchamber of the mosque (Shabestan) which is anchored on circular pillars, adorned with extremely beautiful cornices and relates to Dailamis period.

Nezam-ol-molk dome and its forty pillars around it which have been placed in the second cloister of the mosque and built in between the years 1044 to 1064 A.D.; the dome was built in the reign of Malek Shah Seljukid and consultation of Khajeh Nezam-ol-Molk and is of scarce examples of 
Seljukid kingdom. The front cloister of this brick dome has been built at 12 century and its roof is mixed with large muqarnas. The dome was adorned with the most beautiful patterns of brick and plaster. The aperture of the southern dome is 15 meters.

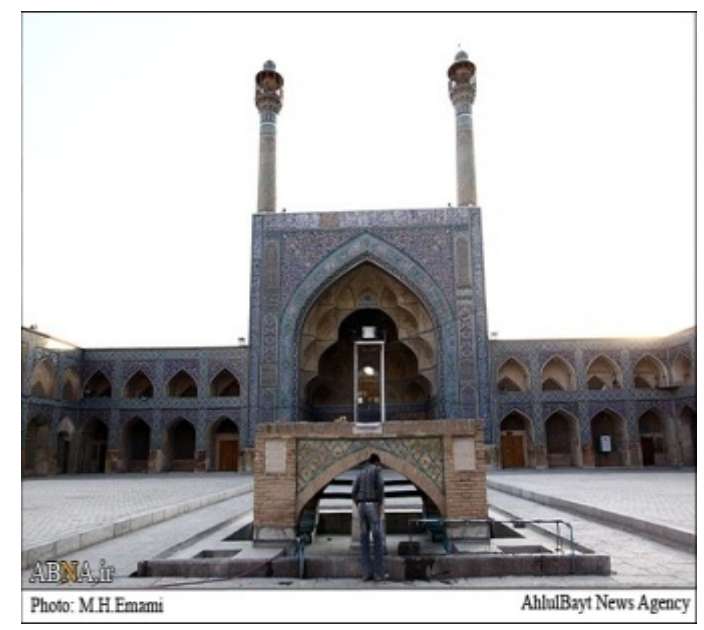

Figure 1. Jame Isfahan mosque

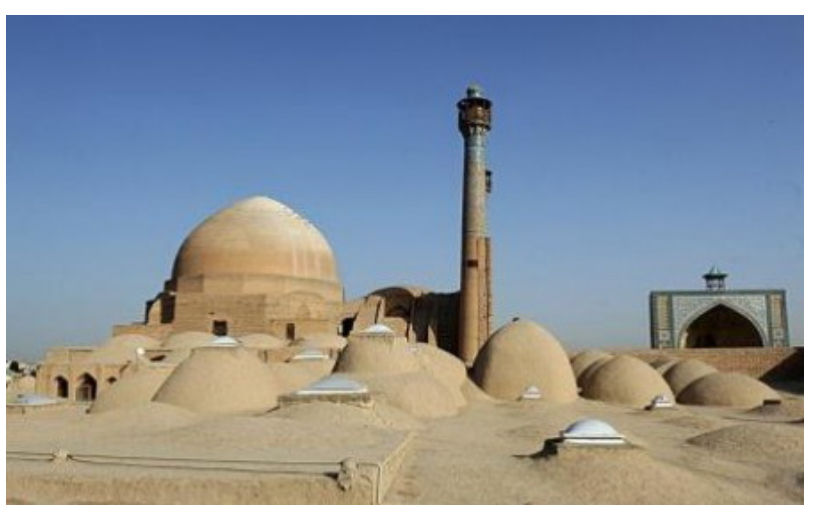

Figure 2. Nezam-ol-molk dome

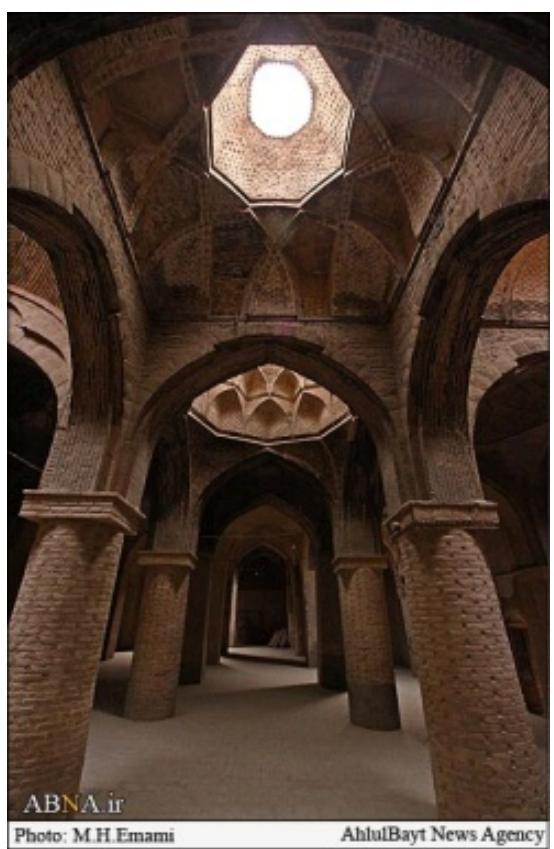

Figure 3. The columned bedchambers

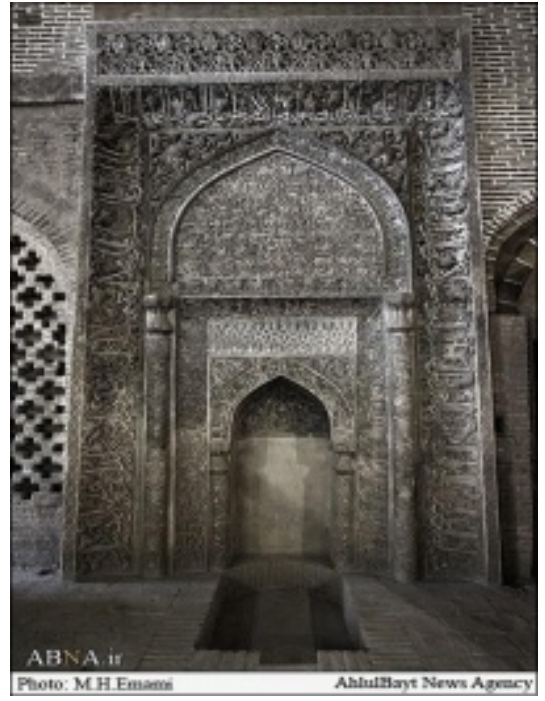

Figure 4. Oljaito altar

Taj-A 1-Molk do me was built at 1060 A.D. which has been located at the Northern part of the mosque-yard and is the opposite of Khajeh Nezam-al-Molk dome. Its construction is introduced to Taj-al-Molk, another vizier in Seljukid era. The dome is known as Taj-al-Molk dome and has the undertone of fire temple. The height and diameter of this muddy dome is 19.5 and 10.5 meters respectively.

The clo ister known as Sofeh Saheb which has been built at Seljukid kingdom and its decorations are related to Gharaghoiounlu and Safavid eras.

The western cloister known as Sofeh Ostad which was built as Seljukid kingdomand adorned at Safavid period with tiles. So feh Shagerd has been located in front of th is cloister and built at Selju kid kingdom; adorations related to Ilkhanan and Safavid period in $14^{\text {th }}$ and $17^{\text {th }}$ century were added to it.

This cloister is without any tile adornment and has been adorned with brick muqarnas. There is an exquisite a labaster in this cloister with plates and epigraphs around it. Sofeh Omar has been located at the final part of the eastern side of the building with decorative and historical lines on the ceiling.

On the North of Ostad cloister is a small bedchamber which includes the most beautiful plaster altar. bedchamber is known as Ul-Jaito mosque; the name of Sultan Khodabandeh Ilkhan before his conversion to Islam, who named himself "Lord Servant," and his sophisticated vizier Muhammad Savi and the date of construction, 1289 A.D., is seen. The mosque includes nine altars and two minarets (around the Southern cloister). A number of historians have mentioned two other minarets on the South and two more on the North which are ru ined totally. The most beautiful inlaid pulpit in Jameh Mosque of Isfahan is available who production late is not clear. From Ul-Jaitu Mosque we get to Beit-Al-sheta winter bedchamber according to which epigraph it has been built in the command of Emad Ebn-Al-Moza far Varzaneyi in Timurid kingdom. That's why it is known as Emad bedchamber as well. The glorious bedchamber includes short thick pillars and tent-like rooms. 
In the middle of each arch spring is a transparent alabaster which casts bedchamber light. The main courtship of the mosque includes four cloisters on the North, South, East and West (Figs 1-4)[6].

\section{Goharshad Mos que, Azeri style, Timurid period.}

Iran was two times attacked by the Mongols in the 13th and 14th centuries. In the 14th century, Timur launched an attack on Iran with extensive destruction and massacre. After Timur's death, his son Shah Rukh assumed power. He was interested in creating art work and began to construct religious buildings.

Among the most important religious monuments of this period we can indicate Goharshad Mosque which was constructed by the command of the wife of Shah Rukh in the early 15 th century, in the south of the Holy Shrine of Imam Reza (Imam of Twelver Shi'a Islam). Goharshad grand mosque building has been made up of brick and plaster in the Eastern architectural style. The whole area of the mosque is almost 9410 square meters with peripheries 109.30 meters from the West, 107.80 meters from the East, 87 meters from the North and 98.65 meters from the South.

There are seven entrance gates for the mosque nowadays including an entrance from the Holy Shrine. A large courtship has been located in the middle of the mosque with $50 \times 55$ meter approximate dimensions which is restricted to four cloisters named (Maqsureh) Southern, (Dar-Al-Syadeh) Northern, (Haji Hassan) Eastern and (Aqua Cloister) Western from the mail navigational points and twp-storey porticos.

The dome of the mosque which has been located on the Maqsureh cloister and made up of turquoise tile. The height of the dome is 40 meters with a 10 -meter diameter. The underneath armature is known as skullcap while the second armature of the dome is external which is visible from the outside. Based on the experts' ideas, the dome was removed completely in 1962 and a new dome was made with new tools and stuff. The dome is built on a low-height cylindrical leg and the main part of the dome begins with a smooth arc and takes the shape of a hemisphere with and extended axis which makes an innovatively beautiful form. The dome is thick and ventricular. The tiling around the dome is homogenous turquoise tile.

Maqsureh cloister is the biggest one in the mosque which is known as Qiblah cloister too. The dome has been located on top of it and the altar has been positioned inside. The length of the cloister is 37 and its gate is almost 13 meters.

The Northern cloister. This shallow cloister is known as Simp le Clo ister and has a way to Dar-Al-Syadeh. The ceiling of the cloister has been covered with tiles of white on the background and yellow Kufi handwriting and Chinese loops. It includes borders with plant drawings which gets to the front cloister, covered with brick and tile.

The Western cloister. The cloister is known as Aqua Cloister and leads to Sheikh Baha-Al-Din Ameli, Islamic Republic courtship and Dar-Al-Velayat portico of holy shrine of Imam Reza. An azure dark blue on the background epigraph with white handwriting which has been surrounded by climbing flowers; the surface of the cloister has been filled with diaphoretic tiles with plant inscriptions. There are bricks and tiling at the end of the cloister which depicts beautiful loops. Both sides of the clo ister inside it, there has been closed vaults which include brick and tiling and turquoise is the main color on the walls, which makes a wonderful display on the brick background.

The floor of the cloister has been furnished with alabaster and plinths are covered with dark alabaster. The whole ceiling has been coated with tiles and 21 octagon stars has been surrounded by an epigraph. There are white epigraphs on a dark azure background inside the cloister.

The Eastern Cloister. This cloister is known as Haji Hassan. The floor, like others, has been furnished with alabaster and plinths have been coated with dark a labaster.

The bedchambers. On three sides, there are bedchambers called Nahavandi, Golpayegani or Milani, Najaf Abadi, Sarabbi of warm bedchamber and Sheikh Gholam Hossein. All the bedchambers have been covered with white plaster, the simplic ity of wh ich tranquilizes the visitor.

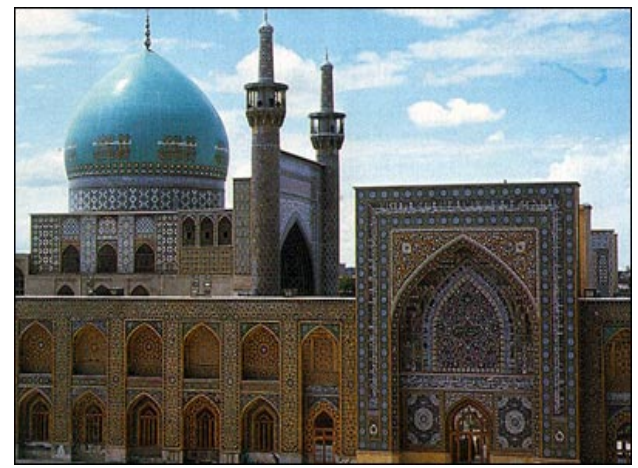

Figure 5. Goharshad mosque

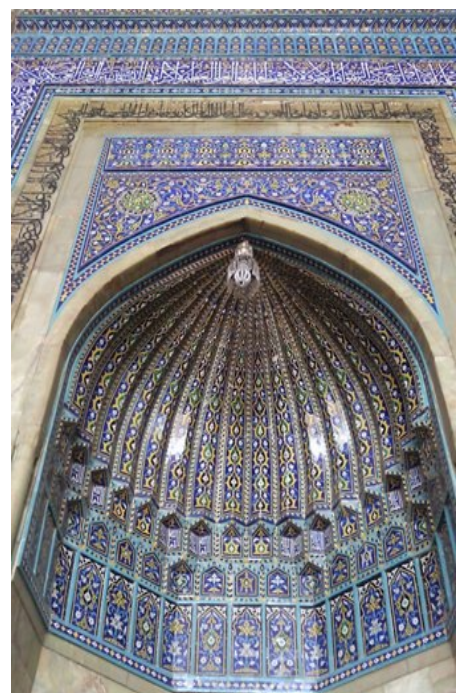

Figure 6. seven colors tiles in ornamentation

Minarets. Minarets of the mosque have been placed on the two sides of the Maqsureh cloister which are 41-meter long cylinders from the floor. The diameter of each minaret is 3 meters. Patterns of flowers and plants or sharp narrow leaves which have been worked on diaphoretic tiles would be mentioned as secondary patterns. The bas is of each nosegay 
begins from the outside surface which is rare on the two side of the clo ister. There are flowers on both minarets on which the names of God were mentioned; the nosegays have been filled with diaphoretic tiles which are made in compilation with brick. The complication has been checked and flower patterns of the tiling divided into two parts. The number of flower patterns get to almost 180 in each nosegay.[7],[8],[9] (Figs. 5- 7)

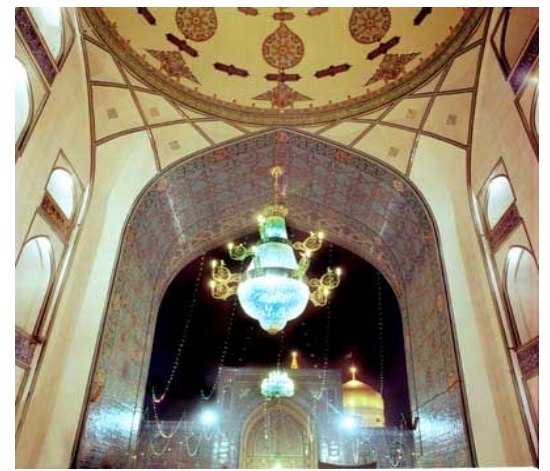

Figure 7. Maqsoureh cloister

Sheikh Lotf Allah Mosque, Isfahani style, Safavid period. The mosque of Sheikh was built by command of Shah Abbas Safavi. In the first half of 17th century. Sheikh Lotf Allah who was a religious scientists from Lebanon came to Iran and became Shah Abbas's father-in-law. The mosque was built for him as a place to pray and a school which was located in the east of Naghshe Jahan Square and opposite the Ali Qapu palace. This mosque is unique in the form of dome and tile work. Since the mosque has been located on the east side of the square, inevitably the entrance will be on the east side of the square and if they were to build the mosque in this direction, navigation would have been perplexing. To solve this problem, a corridor was built from the entry of the mosque to the left and then to the right. Although the building of the mosque is in the east and from the exterior view one can perceive that its wall is in north to south direction, the altar is built in this wall and it is toward Qiblah. In such a way that in the exterior form of the mosque there is no sign of tilt and angle[3]. The dome of Sheikh Lotf Allah is one the various uni-covered domes of the Safavid kingdom which with its low height is considered as a suitable cover for its courtship. On the other side, its height is that it can parade next to the large square. The curvature of the dome is turned inside from the great bump and has made the pinnacle of the dome. Such structure puts the thick walls of the mosque under the pressure and includes cream decorations with dark blue patterns. The diameters of the walls which could be measured from the windows are almost 170 centimeters. The internal walls start from an octagon. The octagons are surrounded by turquoise rope-like tiles and beautiful lines enclose the octagonal sides as of a frame. The lines are made with bone white tiles amongst dark blue ones; the degrees of these octagons base a large curve; therefore, the gradual curvature of the dome conceals the beginning point of the curvature and its great circle. Kite-like embowed walls divide the curvature of the dome into octagonal sides.
The other side tends to a normal curvature; the curvature in whole is so normal that is rarely felt or seen. The internal tiling of the dome from the beginning to the end is almost the same size which constitutes the adornment of the dome. The lateral walls of the courtship are decorated with attached blue flowers and bushes with a cream handwriting. The internal decorations include large repetitious yellowish golden stars which are covered with interweaved iv ies. There are holes in the diameter of the dome on an orderly basis which are closed by plaster windows from the inside and outside.

Sheikh Lotf Allah mosque has some critical differences with other mosques of Isfahan. It includes no courtship as well as a minaret. The do me of the mosque and the two roofs are monolithic. The mosque, in contrast to others, is small and is a small chapel, indeed (Figs. 8-10)

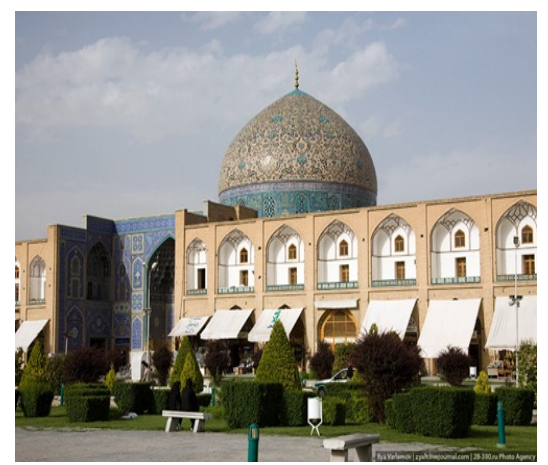

Figure 8. Sheikh Lotf Allah mosque with cream dome

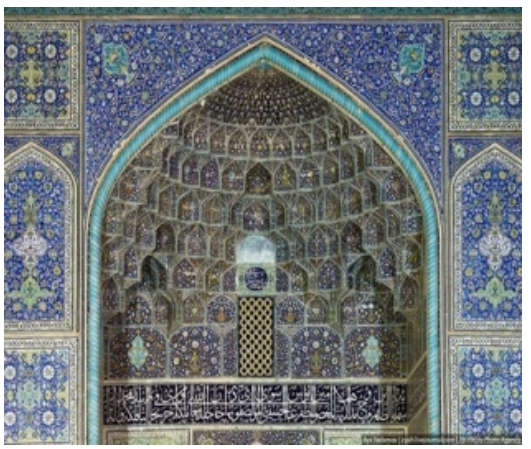

Figure 9. Interior ornamentation

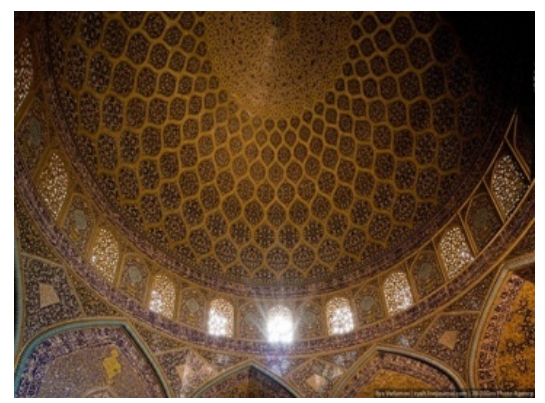

Figure 10. Interior ceiling ornamentation

\section{Discussion}

Above mentioned mosques have three different styles. We could see a tend from simple to complex structure. For example, in Jameh Isfahan mosque, Khorasani style is 
observed with rectangular plan, bedchamber space or 40 columns, simple and without ornamentation of the bare bricks and decorative bricks and mud sometimes use a single minaret in the north building, elliptical arcs, egg width. Goharshad mosque has been built based on Azeri style with construction of large buildings, according to the vertical proportions, making the The porch with rectangular plan, diversity in the the porch, the use of decorations, such as plaster, tile and tile embossed gold, making the throat or shoot. Finally, Sheikh Lotf Allah mosque has been built as Isfahani style. It is identified with rectangular plan or a simple polygon, high quality materials and durable porch plans, the use of tile seven colors[10],[11].

\section{Conclusions}

With regard to the architecture of mosques in Iran, it can be noted that in general architecture of pre-Islam has been very influential in the construction of mosques in Iran. The implementation of minaret, dome and the porch which are related to the Achaemenid, Parthian and Sasanid confirms this issue. In fact, the utilization of these buildings in mosques was aligned with the goal of building mosque which is the same as prayer, solitude and deep meditation of self and the creation. In mosques, the strive is to create tranquility, silence and attention to God which is characterized in its water, color and lighting. In Islam, flowers and plants and birds were only to be inserted, for no prophet is portrayable and God cannot be perceived and mosque is the place for the manifestation of the visage of God which plants and birds are a symbol of God. As it is comprehended regarding the Kingdom periods, Selijukid period mosques resemble those of Arabs and lack ornamentation and tile work. Decoration was done on brick and Muqarnas and they were normally single-minaret. In the Timurid period huge buildings construction was a show of strength which resulted in the construction of big mosques. Tiling with seven special colors and stemmed domes are the features of this period. In the Safavid period mosques we can observe the apex of ornamentation and tiling, mosque has become a special art work which for a Muslim establishes spiritual state and brings visual joy as well, and for a tourist, miracle of drawings and beautiful graphic is displayed at the mosque.

\section{REFERENCES}

[1] Ardalan N., Bakhtiar, L, The sense of Unity, 1991. (In Persian).

[2] Javadi, A, Iranian Architecture, Mojarad publisher, 1984. (In Persian).

[3] Afshar Hamdari, Gh, Iran architecture, $2^{\text {nd }}$ ed. Farhangan publisher, Tehran, 1991, (In Persian).

[4] Pirnia, M. K, Islamic Architecture of Iran, Elm va Sanat University of Iran, Tehran, 1995. (In Persian).

[5] Soltanzadeh, H, Presentation of water in Iranian architecture, Proceeding of $1^{\text {st }}$ congress of co-thinking of Art and nature elements (water, soil, fire, air), Art culture school, 1995 (In Persian).

[6] Golombek, L, Wilber, D, The Timurid Architecture of Iran and Turan. Princeton: Princeton University Press. 1988.

[7] Willber, D. N, The architecture of Islamic Iran: The Il Khanid period, (Princeto monographs in Arts and Archaeology, Praeger publisher, 1988.

[8] Afsar, K \& Kiani, M.Y, Timurid architecture in Iran and Turan, 1996. (In Persian)

[9] Byron, R, "Timurid Architecture". In A Survey of Persian Art (Arthur Upham Pope and Phyllis Ackerman, eds.).: Soroush Press, 1119-1164, Tehran, 1977.

[10] Gharehvashi, M. (translated), Dialofoa travel account in Qajar period, Khaiam publishing. Tehran, 1982. (In Persian).

[11] Rafiei Mehrabadi, A, National works of Isfahan, National works of Iran publishing, Tehran, 1974. (In Persian). 